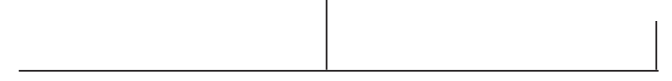

Rev. Latinoam. Psicopat. Fund., São Paulo, 16(4), 597-609, dez. 2013

\title{
A fantasia não dorme: linguagem da noite e males da ilusão*1
}

Paulo José Carvalho da Silva*2

Na continuidade dos estudos sobre os males da alma segundo a cultura luso-brasileira e europeia dos séculos XVI ao XVIII, este artigo investiga diferentes interpretações e usos das narrativas oníricas. Em especial, trata de desordens causadas pelos excessos do gozo entendidos como engodos do mundo.

Palavras-chave: Males da alma, sonho, imaginário, gozo, cultura luso-brasileira

${ }^{* 1}$ Pesquisa realizada com apoio do Conselho Nacional de Desenvolvimento Científico e Tecnológico - CNPq (Brasília, DF, Br) (Bolsa de produtividade em Pesquisa).

*2 Pontifícia Universidade Católica de São Paulo - PUC-SP (São Paulo, SP, Brasil) 
Do início da Idade Moderna, dentre as reflexões sobre as atividades da alma desgarradas da razão, pode-se destacar discursos sobre as potencialidades do sonho e limites da lucidez. Havia uma literatura, atualizadora da tradição antiga, que propunha chaves interpretativas da linguagem noturna, relacionando-a ao passado, ao presente e mesmo ao futuro do sonhador, cujas alegorias predeterminadas devem ser lidas em relação ao pensamento da época sobre a retórica e a filologia, como esclarece Jeffrey Masten (2000). Havia também quem defendesse que um sonho encerra uma multiplicidade aberta de significados, isto é, a imagem sonhada não corresponde diretamente a uma coisa da experiência diurna, justamente porque a linguagem própria do sonho é plurívoca, ela forma e deforma a mensagem, convocando o próprio sonhador a uma arte interpretativa que consiste em traduzir, dar significado aos estados internos, nomear o que está oculto (Le Brun, 2004).

Para Maria Jordán Arroyo (2006), embora fosse prática controversa e mesmo recusada como superstição pela ortodoxia católica, a literatura ibérica que orientava a interpretação dos sonhos indica que os homens e as mulheres do início da Idade Moderna se preocupavam com a saúde, a vida afetiva, o desterro, as dificuldades econômicas, a honra e a morte.

A coletânea de estudos sobre os modelos filosóficos e literários acerca dos sonhos do antigo regime, organizada por Nathalie Dauvois e JeanPhilippe Grosperin (2003), mostra que a escrita de sua história implica resgatar as representações mentais dos seus narradores, como as miragens do desejo e da fé, as formas das paixões da alma, a imagem dos limites corporais, os jogos entre memória e esquecimento, o universo fantasmático, os ritos simbólicos e mesmo os diferentes graus de recuo especular e de reflexão sobre os prolongamentos da realidade diurna. Seja ao narrar os sonhos, seja ao pensar o sonhar e sua verdade, os escritores da passagem da Idade Média à Moderna revelam modos de representar e compreender a si mesmos no mundo. Para além do desejo de apreender a experiência, desvendar o significado ou explicar sua gênese, havia um múltiplo uso da 
inteligência, da plasticidade e da eloquência da linguagem do sonho, verdadeiro ou inventado.

Na continuidade dos estudos sobre os males da alma segundo a cultura luso-brasileira e europeia dos séculos XVI ao XVIII, este artigo, por sua vez, investiga discursos sobre o sono, o sonho e as perturbações da fantasia em diferentes gêneros de escritos.

\section{A fantasia não dorme}

Um soneto anônimo seiscentista faz uma Descrição da noite, para falar de um silêncio que não apazigua a mágoa:

Como está toda a terra escurecida!/ Como corre calada aquela fonte!/ Já o Sol não se avista no Horizonte,/ Já nenhuma outra luz é conhecida. (...) Com o gado o pastor à aldeia chega,/ Nos bosques dorme a fera, o peixe na água/ Tudo enfim ao silêncio já se entrega./ Mas em meu peito triste, ardente frágua,/Por um tênue momento não sossega/ O estrondo, que motiva a minha mágoa. (Pécora, 2002, p. 170)

Manuel Maria Barbosa du Bocage (1765-1805), mais conhecido por sua poesia burlesca e satírica, discorre sobre uma solidão intensificada pelo silêncio da noite, em um de seus poemas dedicados à Insônia:

Já sobre o coche d'ébano estrelado/ Deu meio giro a noite escura e feia;/Que profundo silêncio me rodeia/ Neste deserto bosque, à luz vedado! Jaz entre as folhas Zéfiro abafado,/ O Tejo adormeceu na lisa areia;/ Nem o mavioso rouxinol gorjeia,/ Nem pia o mocho, às trevas costumado: Só eu velo, só eu, pedindo à sorte/ Que o fio com que está minha alma presa/À vil matéria lânguida me corte: Consola-me este horror, esta tristeza;/ Porque os meus olhos se afigura a morte/ No silêncio total da natureza. (Bocage, 1989, p. 33)

Em se tratando de um autor "pré-romântico", é mais provável que esta insônia seja ideal, modelada e, mesmo, modelar. Alcir Pécora (2001) adverte que uma leitura psicologizante dos poemas de Bocage seria, no mínimo, ingênua. Assim como a produção poética de sua época, os versos do rei dos brejeiros, em suas palavras: "obedecem estritamente à lei do decoro, da aplicação ao caso das tópicas adequadas, da busca de efeitos particulares, sem chegar à ideia de constituição de uma profundidade psíquica ou que se possa distinguir dos efeitos persuasivos que fabrica" (p. 220).

Não se trata, portanto, da intimidade do poeta expressa segundo um dever de sinceridade, mas de uma composição que cria o efeito, inventa uma cena, a partir dos elementos convencionais das práticas letradas da época. Nesta perspectiva, a análise 
do poema não nos permite, na busca de uma compreensão das perturbações da alma vividas no passado remoto, uma generalização de um caso particularíssimo de sofrimento testemunhado pela escrita. Melhor do que isso, ela nos aponta para uma afirmação menos arriscada de que, no período, alguns significantes prevaleciam quando se tratava de representar os males da alma na calada da noite: silêncio e morte.

No campo médico, desde pelo menos Hipócrates, pensava-se que o sono em excesso e, sobretudo, a falta do sono seriam prejudiciais à saúde. Aliás, lê-se nos aforismos hipocráticos que uma doença que perturba demasiadamente o sono é mortal, ao contrário da enfermidade que pode ser atenuada pelo mesmo. Inclusive, considerava-se bom sinal quando o sono faz cessar o delírio. Ideias amplamente retomadas nos séculos XVI, XVII e mesmo XVIII.

Segundo a tradição dietética, a noite é o tempo do repouso e o sono nutre, aquece e umedece, como defende, por exemplo, o médico Francisco Sanches (1999a/1586), em seu "Comentário ao livro de Aristóteles Da longevidade e brevidade da vida", de 1586. Justamente porque o sono era descrito como uma prisão dos sentidos externos, para que as entranhas pudessem ser adequadamente alimentadas, isto é, um recolhimento necessário para a conservação da vida, a sua falta era considerada a origem de muitos males do corpo e também da alma. O médico lusitano Francisco da Fonseca Henriquez, que dá continuidade à tradição dietética, no Âncora medicinal para conservar a vida em saúde, de 1721, chega a falar de dores agudas, febres ardentes, paralisias, convulsões, delírios e frenesis, entre outros males grandes e perigosos advindos do excesso de vigília.

Se não dormir enquanto todos dormem podia significar estar envolvido pela sombra da morte, o próprio sono também era representado como uma prévia de sua experiência. Pensava-se ser preciso morrer para o mundo por algumas horas para preservar o úmido e o calor da vida no interior do corpo.

$\mathrm{Na}$ tradição espiritual, não apenas o sono era frequentemente comparado à morte, como a própria morte era comparada ao sono, até o juízo final e a ressurreição da carne. Assim, um relativiza o outro, ao se referirem, no fundo, ao modo como se viveu e as ações meritórias ou virtudes, a serem recompensadas num além da existência temporal. Por exemplo, segundo o influente jesuíta francês Louis Richeome (1554-1625), em seu La peinture spirituelle, de 1611, para quem soube viver, a morte e o sono são irmãos gêmeos. Ao adormecer: é uma pequena morte, privação dos sentidos, sono de bronze. Ao morrer: o corpo é uma carcaça sem alma, dorme um sono de ferro. Porém, dependendo de como se viveu, segundo a doutrina, pode-se ainda despertar.

Acontece que, entre os vivos, a fantasia nunca dorme totalmente: formados com as imagens coletadas durante a vigília, as chamadas espécies, os sonhos são produzidos quando o corpo adormece e o espírito domina a casa. Assim explica Francisco Sanches (1586/1999b), em seu virulento "Comentário ao livro de Aristóteles Da adivinhação pelo sonho": 
A alma recebe e resolve, como que através de uma nuvem, as espécies oferecidas, e, visto que então não está completamente senhora de si, confunde as imagens verdadeiras com as falsas, não julgando rectamente, nem discernindo bem entre umas e outras, sem, contudo, deixar de receber as imagens oferecidas; excita-se a si e ao corpo para evitar as coisas nocivas, para repousar nas coisas agradáveis, para desejar e conseguir as coisas necessárias e úteis. (p. 176)

A medicina humoral fundamentava diferentes modalidades de codependência ou harmonia entre os estados mentais e a disposição fisiológica (Martins, Carvalho da Silva, Mutarelli, 2008). No célebre Regime (1623) do teólogo da universidade de Louvain, Léonard Lessius (1554-1623), lê-se que os humores dominantes acompanham o campo das fantasias, dos sonhos e das paixões da alma. Por exemplo, corresponde à bile, além do calor, a qualidade do amargor, também presente na fantasia que apreende os discursos e ações dos outros como disposição contrária, algo pugnativo ou até mesmo injurioso, que clama por vingança. O fleuma, por sua vez, caracteriza-se pelas qualidades de frio e úmido. Em consonância, a apreensão do mundo externo do fleumático é marcada pela apatia, tendendo mais para a prostração ou a maledicência.

Supunha-se que o complexo psicofísico dos temperamentos condicionava o tom afetivo dos sonhos. Conforme a síntese de Sanches:

(...) quando predomina o humor melancólico, sonha com cadáveres, mortes, ferimentos, serpentes, cruzes, lutos e outras coisas tristes; quando predomina o sangue, sonha com núpcias, danças, banquetes, risos e outras coisas alegres; quando predomina a bílis, sonha com rixas, fogos, incêndios e relâmpagos. (Sanches, 1586/1999, p. 196)

A tese era conhecidíssima no período. Até o padre Antônio Vieira (1608-1697), ele mesmo grande sonhador e intérprete de um sonho português de grandeza, dentre uma teia mais ampla de narrativas oníricas sobre a origem e o destino profético da potência cristã (Lima, 2010), cita a teoria médica dos sonhos como manifestação dos estados d'alma:

Galeno, para conhecer os humores do enfermo, manda observar os sonhos: e tambem se podem observar para conhecer os affectos, que são humores da alma. O melancholico sonha coisas tristes e tragicas, o sanguinho sonha felicidades e festas, o colerico sonha guerras e batalhas, o fleugmatico creio que não sonha, porque não vive. (Vieira, s.d./1951, p. 42)

\section{A vida é sonho}

Definia-se a vida humana não apenas em relação a como se pensava o destino após a morte, mas também nas continuidades e descontinuidades entre a vida com 
olhos abertos ou fechados, pois, afinal, para o sujeito, tudo o que experimenta sonhando ou acordado fazia parte de seu vivido.

Talvez justamente por ser tão vívido que funcionava comparar a vida ao sonho. Aliás, o tema da vida mundana enquanto um sonho foi amplamente difundido na literatura moderna. Do contexto ibérico, a obra mais famosa é, certamente, a peça La vida es sueño, do madrilenho Pedro Calderón de la Barca (1600-1681), cujo fim diz:

¿Qué os admira?, ¿que os espanta, si fue maestro un sueño, y stoy temiendo en mis ansias que he depertar y hallarme outra vez en mi cerrada prisón? Y, cuando no sea, el soñarlo solo basta: pues así llegué a saber que toda la dicha humana en fin pasa como sueño, y quiero hoy aprovecharla el que me durare, pidiendo de nuestras faltas perdón, pues de pechos nobles es tan próprio el perdonarlas. (p. 122)

Esse topos foi largamente empregado nas letras ibéricas e também do além Pirineus. Por exemplo, aparece em Octonaires sur la Vanité et Inconstance du Monde, principal obra poética do calvinista Antoine de la Roche-Chandieu (1534-1591):

XLIV. Eu vi, eu vi que o mundo é um sonho,/Assim que a voz de Deus me despertou,/Pois no Mundo há só mentira;/O olho é fechado e o espírito perturbado,/ Tudo é noite, o homem está fora do homem,/Pensando por opinião vã,/Sentindo apenas sua própria paixão,/Não querendo que se perturbe seu sono. (1979/1583, p. 88 ; tradução nossa)

Jean-Baptiste Chassignet (c.1570- c.1635), advogado e poeta, também aplica o tema nos sonetos que compõem seu Le mepris de la vie et consolation contre la mort. O título do livro, por si só, explica a pertinência de se retomar tal lugarcomum, por exemplo, em:

XCVIII. (...) O que é a sua vida? Uma mentira frívola/Que sob a sombra do real acaba por decepcionar,/Um sonho que não tem mais nem força nem poder/Assim que os olhos no despertar suas pálpebras descolam. (...) Pois vocês negligenciam doravante o bem/Durável e permanente por um ponto que não passa/de um sopro, uma mentira, um sonho, uma fumaça. (1967/1594, p. 105; tradução nossa)

Há, nestes últimos casos, uma diminuição da experiência do sonho enquanto mentira ou coisa vaporosa, sem consistência ou alcance, mas na mesma medida em que a totalidade da existência temporal era considerada ilusória, isto é, projeções na caverna, sombras de um outro sol. O que remete ao tema da transitoriedade e do engano, ou seja, da brevidade da vida, da dor do tempo e do mundo como território da inconstância, já tratado nesta seção (Carvalho da Silva, 2012).

A questão "estou acordado ou sonhando?" foi recolocada sob diversas formas em diferentes gêneros de escritos. Ela aparece não apenas no teatro de Calderón de la Barca, mas também de Shakespeare ou de outros dramaturgos menos conhecidos. 
A ideia segundo a qual o dorminhoco pode acordar, o bêbado pode recuperar a lucidez e o doente pode até se curar, mas apenas se pode escapar do teatro do mundo por meio da morte retoma a analogia da vida como sonho, na formulação da patrística, por exemplo, no pensamento de João Crisóstomo (ca. 347-407), como bem ressalta Jean-Pierre Cavaillé (2003), mesmo que a metáfora já estivesse presente na poética grega antiga.

O problema metafísico da distinção entre o sonho e a vigília serviu de argumento para a tradição céptica, que inclui ainda Platão, Sexto Empírico, Galeno e Cícero, ponderar sobre a existência de um pensamento no sonho e, sobretudo, julgar que o sonhador crê estar acordado durante o mesmo ou, na expressão de Cavaillé (2003), vive "uma ficção do homem acordado" (p. 118). O mesmo argumento foi renovado nos séculos XVI e XVII, por pensadores da envergadura de Montaigne, Hobbes, Pascal e Descartes.

Assim como outros pensadores modernos influenciados pelo cepticismo, não é o problema da vaidade do mundo o que preocupa Descartes, mas, sim, a certeza epistêmica e, neste sentido, suas meditações sobre a sensação de realidade do sonho limitam-se à indagação sobre qual medida a experiência sensorial atual é confiável, conforme enfatiza Tony James (2002). Se por um lado, na época, havia um gosto particular pelo jogo de ilusão, presente no teatro, nas máquinas ópticas e nas anamorfoses, por outro, criava-se meios de busca da verdade. Aliás, na Primeira meditação, quando examina as ilusões sensoriais, Descartes chega a parear o sonhador ao louco, na esteira de vários cépticos antigos. A propósito, Janet Broughton (2005) defende que as impressões oníricas são muito mais comuns e cotidianas do que as alucinações, tornando o argumento do sonho mais forte. Todavia, somadas as alusões, escancara-se a radical dificuldade humana de corrigir o próprio julgamento.

Por outro lado, o relato de sonhos, sonhados ou inventados, podia fazer parte de um recurso retórico de persuasão visando mover a imaginação, juntamente aos símiles, parábolas e visões. Peter Mack (2004) lembra que a retórica e a poética permitiam um acesso privilegiado à imaginação, que por sua vez era muito importante por causa de seu poder sobre as emoções e sobre a própria razão. Não se duvidava da eficácia da fantasia na comunicação.

Desde a Idade Média, ficções oníricas serviam de enquadre para narrativas alegóricas de peregrinações (Maupeu, 2003). Em O Peregrino (1678), do puritano John Bunyan (1628-1688), a travessia do personagem Cristão, da cidade da destruição à cidade celeste, é relatada como se fosse uma sequência de sonhos do narrador. Trata-se de um percurso alegórico edificante, passando por lugares como o Pântano da Desconfiança, o Desfiladeiro da Dificuldade, o Vale da Humilhação ou a Feira da Vaidade, repletos de perigos e engodos, para mostrar que o país desejado, para além das Montanhas das Delícias e, é claro, do Rio da Morte, não acolhe quem se distancia da "verdade", por mais que os atalhos do mundo assim o prometam: 
Pena foi que o meu sonho não acabasse com tão doces impressões. Depois de fechadas as portas, olhei para trás e vi Ignorância, que chegava à margem do rio; passou depressa e sem metade das dificuldades que os peregrinos tinham encontrado. E aconteceu assim, porque estava ali um barquinho chamado Vã-Esperança, que o ajudou a passar na sua barca. Ignorância subiu também a montanha em direção à porta, mas ninguém foi ao seu encontro para o ajudar, nem para lhes dirigir uma palavra de estímulo ou de consolação. (Bunyan, 1678/2004, p. 226)

Ao mostrar, simultaneamente, verdade e engano, a ficção onírica serve para revelar que mesmo desperto alguém pode estar iludido pela ignorância do mundo. Assim, na parábola de Bunyan, por não ter o "diploma” que legitimasse sua entrada na cidade da glória, Ignorância é violentamente banida:

Comunicado ao Rei o que acontecia, ordenou Ele aos Resplandecentes que atassem Ignorância de pés e mãos, e o lançassem fora; e vi que o levavam pelos ares até a porta que eu tinha visto na fralda da serra, e que dali o precipitaram. (...) E nisto... acordei, e vi que tudo fora um sonho. (p. 226)

Enfim, a linguagem noturna, território da fantasia, servia ao desmascaramento do teatro das aparências e à admoestação sobre o problema dos excessos do imaginário desordenado. Melhor seria, conforme Tony James (2002), a propósito dos limites entre sonho e lucidez, ter um duplo olhar sobre a ilusão, de dentro e de fora, mantendo todo julgamento em estado provisório.

\section{Males da ilusão}

A novela alegórica do jesuíta Alexandre de Gusmão (1629-1724), História do Predestinado Peregrino e de seu irmão Precito (1682) propõe uma parábola na qual o topos do Homo viator figura, mais uma vez, na defesa de que a existência temporal é, na verdade, um desterro da verdadeira pátria. O objetivo é mostrar que só haveria um roteiro certo nesta vida, através da história de dois irmãos, um chamado Predestinado Peregrino, casado com a Razão, que obviamente escolhe o dito bom caminho, segundo a moral católica contrarreformada, e após encontros edificantes, conquista a salvação eterna. Por sua vez, seu irmão Precito, casado com a Própria Vontade, não faz a mesma escolha e segue um descaminho de excessos e satisfações imediatas que, ao cabo da existência temporal, seriam proporcional e eternamente punidos.

As desventuras de Precito também podem ser lidas como a descrição dos múltiplos males da alma, cuja origem era atribuída à entrega aos engodos do mundo. Para começar, sua esposa, a Própria Vontade, era cega dos dois olhos e seus primeiros rebentos estudaram na escola da mentira, ao passo que os filhos do irmão virtuoso estudaram boas artes na escola da verdade. 
As paradas de Precito em sua descida rumo à perdição e ao exílio absoluto da noite eterna são mais do que uma simples alegoria dos vícios, em oposição às virtudes da prudente e temperante família do irmão, são também estágios de um complexo acumulado de condições psicopatológicas.

Já na primeira paragem, papai Precito, mamãe Própria Vontade e os filhinhos Maus desejos e Tortas intenções são bem acolhidos e se sentem em casa, logo se aclimatando ao Palácio dos Enganos:

Os Edifícios da cidade todos eram sem alicerce, os vizinhos todos mercadores, os contratos todos usuras e simonias, a moeda toda falsa, a virtude hipócrita, a amizade aleivosia, e quando muito conveniência, enfim Cidade onde governava o engano, e Mentira, e que se interpreta casa de Vaidade. (Gusmão, 1682, in Massimi (Org.), 2012, p. 64)

Precito, que lembra um pouco o tal do sujeito desorientado de quem tanto se fala hoje em dia, segue, com sua família, sua viagem para Babilônia, distanciando-se cada vez mais do "roteiro de vida", abalizado pela teologia moral aristotélicotomista defendida pela Antiga Companhia de Jesus. Ele goza de uma breve estadia na cidade dos passatempos e diversões inconsequentes, até um novo pouso, desta vez, na cidade das liberdades desenfreadas, regida pelos incestuosos Apetite e Fantasia. Lá, rege o impulso da vontade, ou, na descrição do influente pedagogo seiscentista: "tudo quanto Fantasia representava a Apetite, tudo Apetite punha logo em execução". Atmosfera propícia para o crescimento da família, porém sob o efeito do mal da terra, o Melindre:

Aqui teve cinco filhos, Voluntário, Melindroso, Amuado, e Contumaz. Teve mais outras cinco filhas muito semelhantes aos seus irmãos: Inobediência, Contumácia, Preguiça e Relaxação, que era uma rapariga bem estreada, mas muito preguiçosa e distraída, que engana aos Mancebos e também aos velhos. (Gusmão, 1682, in Massimi (Org.), 2012, p. 106)

Ao atravessar uma região muito fértil, onde manava mel e manteiga, a família enganada e voluntariosa chega à Cidade do Deleite, onde governavam Regalo e Delícia, com ajuda do mordomo Bemmequero. Seus habitantes deixavam de comprar pão para a boca, para comprar tabaco para o nariz; muitos se endividavam para manter bela a cabeleira; outros se deleitavam com banquetes enquanto os seus filhos não tinham o que comer; outros ainda vestiam de gala os pajens enquanto suas próprias filhas andavam nuas, entre outros caprichos do gozo soberano.

O mestre da norma Alexandre de Gusmão considera tanta voluptuosidade desordenada a fonte de males da alma, marcados pela falta de vigor e pelo relaxamento no cuidado de si:

Adoeceu aqui do mal comum da terra, que chamam Mimo, e deste mal se lhe originam vários achaques, a saber, Preguiça, Descuido, Frouxidão, Tibieza, com que tomou tal fastio aos medicamentos, com que o mimo se cura, convém a saber, 
penitência e rigor, que em lhe falando neles notavelmente se alterava. (Gusmão, 1682, in Massimi (Org.), 2012, p. 131)

Na penúltima estação, Precito também contrai o mal da terra, que embota o sentido e as potências da alma, jogando-o ainda mais no esquecimento dos ditames da religião. Ao final da jornada, o que parecia doce sonho revelar-se-á amargo pesadelo, na danação eterna, prêmio final de suas loucuras, ou seja, por ter tomado os prazeres da vida não para usar como meios, mas para gozar como fim, ao confundir o que é de passagem com o que é de assento.

Como considerações finais, pode-se afirmar que os personagens errantes e entregues ao gozo, como Precito, encarnavam os excessos e os males da ilusão, também referidos em narrativas oníricas e analogias com o sonho produzidas no período. É bem verdade que não havia uma noção clara de intimidade psicológica, mas, sem sombra de dúvida, escrevia-se muito sobre a alma irrequieta. Aquela que não se acalma durante o dia, muito menos à noite; seja ao fritar na cama enquanto todos dormem ou na atividade do sonho quando o corpo está inerte. Afinal, como escreve Francisco Sanches (1586/1999b), em sua crítica à possibilidade de adivinhação onírica apelando-se ao sobrenatural, os sonhos revelam as inclinações endemoniadas de nossa própria alma:

Acrescentas ainda que nós, além da razão, sentimos em nós próprios algo que nos impele, no combate, e tanto nos contraria, que algumas vezes o nosso espírito parece guerrear consigo mesmo. Óptimo. Portanto, esse algo são os démones? Que ridículo! A não ser que chames démones ao nosso espírito, que é na verdade um démon, se algum existe, como acima dizíamos. (...) E não leste nos filósofos que a nossa alma tem duas partes, a racional e a irracional, embora isto seja dito bastante resumidamente, se não se entender para além da letra? (p. 176)

\section{Referências}

Arroyo, M. J. (2006). El arte de la oniromancia en la España de la Edad Moderna: un manual desconocido. In F. T. M. Borges, M. A. Peraro (Orgs.). Sonhos e pesadelos na história (pp. 35-48). Cuiabá: Ed. UFMT/Carlini Candiato Editorial.

Bocage, M. M. B. (1989). Sonetos. Lisboa: Europa-América.

Broughton, J. (2005). Dreamers and Madmen. In C. Mercer, E. O’Neill (Eds.). Early modern philosophy: mind, matter, and metaphysics (pp. 9-23). Oxford/New York: Oxford University Press.

Bunyan, J. (2004). O Peregrino. Viagem do Cristão à cidade celestial. (A. H. da Silva, trad.). São Paulo: Martin Claret. (Trabalho original publicado em 1678)

Calderón de la Barca, P. (1999). La vida es sueño. Madrid: Clásicos universales. 
Carvalho da Silva, P. J. (2012, dez.). Transitoriedade ou o desterro da certeza. Rev. Latinoam. Psicopat. Fund., São Paulo, 15(4), 881-890.

Cavaillé, J-P. (2003). «Veillé-je ou si je dors?» Une question sceptique, entre théâtre et philosophie. In N. Dauvois, J-P. Grosperin (Orgs.). Songes et Songeurs (XIIIe-XVIIIe siècle) (pp. 113-128). Saint-Nicolas (Québec): Les Presses de L'université Laval.

Chandieu, A. R. (1979). Octonaires sur la vanité et inconstance du monde. Texte établi, annoté et commenté par F. Bonali-Fiquet. Genève: Droz. (Trabalho original publicado em 1583)

Chassignet, J.-B. (1967). Le mepris de la vie et Consolation contre la mort. Edition critique d'après l'original de 1594 par H.-J. Lope. Genève: Droz/Paris: Libraire Minard. (Trabalho original publicado em 1594)

Dauvois, N.; J. P. Grosperin (Orgs.). (2003). Songes et Songeurs (XIIIe-XVIIIe siècle). Saint-Nicolas (Québec): Les Presses de L'université Laval.

Henriquez, F. F. (2004). Ancora medicinal para conservar a vida em saúde. São Paulo: Ateliê Editorial. (Trabalho original publicado em 1721)

Hipócrates (1994). De l'art médical. (E. Littré, trad.). Paris: Librairie Générale Française.

James, T. (2002). «Veillé-je? ou si je dors?»: le songe et le vrai. In D. Souiller (Org.). Réalisme et réalité en question au XVIIe siècle (pp. 151-163). Dijon: Centre de recherches Interactions Culturelles Européennes.

Le Brun, J. (2004). Jérôme Cardan et l'interprétation des songes. In La jouissance et le trouble. Recherches sur la littérature chrétienne de l'âge classique (pp. 109-136). Genève: Droz.

Lessius, L. (1623). Deux traictez du regime de vivre pour la conservation de la santé du corps \& de l'Ame, iusques à une extreme vieillesse. Traduction françoise du latin par Sebastien Hardy. Paris.

Lima, L. F. S. (2010). O império dos sonhos. Narrativas proféticas, sebastianismo e messianismo brigantino. São Paulo: Alameda.

Mack, P. (2004). Early modern ideas of imagination. The rhetorical tradition. In L. Nauta; D. Pätzold (Eds.). Imagination in the later Middle Ages and Early Modern Times (pp. 59-76). Leuven/Paris/Dudley: Peters.

Martins, L. A. P.; Carvalho da Silva, P. J.; Mutarelli, S. R. K. (2008). A teoria dos temperamentos: do corpus hippocraticum ao século XIX. Memorandum, 14, 09-24.

Massimi, M. (Org.). (2012). A novela História do Predestinado Peregrino e de seu Irmão Precito (1682). Compêndio dos Saberes Antropológicos e Psicológicos dos Jesuitas no Brasil Colonial. São Paulo: Loyola.

Masten, J. (2000). The interpretation of dreams, circa 1610. In C. Mazzio; D. Trevor (Eds.). Historicism, Psychoanalysis, and Early Modern Culture (pp. 157-185). New York/London: Routledge.

Maupeu, P. (2003). La tentation autobiographique dans le songe allégorique édifiant de Guillaume de Digulleville: Le pèlerinage de Vie Humaine. In N. Dauvois; J-P. Grosperin (Orgs.). Songes et Songeurs (XIIIe-XVIIIe siècle)(pp. 49-67). Saint-Nicolas (Québec): Les Presses de L'université Laval. 
Pécora, A. (2001). Máquina de gêneros. Novamente descoberta e aplicada a Castiglione, Della Casa, Nóbrega, Camões, Vieira, La Rochefoucauld, Gonzaga, Silva Avarenga e Bocage. São Paulo: Edusp.

Pécora, A. (Org.). (2002). Poesia seiscentista. São Paulo: Hedra.

Richeome, L. (1611). La peinture spirituelle ou l'art d'admirer aimer et louer dieu en toutes ses oeuvres et tirer de toutes profit salutere. Lyon: Pierre Rigaud.

Sanches, F. (1999a). Comentário ao livro de Aristóteles Da longevidade e brevidade da vida. In Obra filosófica. (G. Manuppela, B. Vasconcelos, M. P. Meneses, trad.). Lisboa: Imprensa Nacional - Casa da Moeda. (Trabalho original publicado em 1586)

Sanches, F. (1999b). Comentário ao livro de Aristóteles Da adivinhação pelo sonho. In Obra filosófica. (G. Manuppela, B. Vasconcelos, M. P. Meneses, trad.). Lisboa: Imprensa Nacional - Casa da Moeda. (Trabalho original publicado em 1586)

Vieira, A. (1951). Sermões. Volume XIII. Porto: Lello e Irmão.

\section{Resumos}

(Fantasy never sleeps: language of the night and the ailments of illusion)

Continuing the sequence of studies on ailments of the soul according to LusoBrazilian and European culture from the sixteenth to the eighteenth centuries, this article investigates different interpretations and uses of dream narratives. In particular, it deals with disorders caused by excess of jouissance, understood as lures from the world.

Key words: Ailments of the soul, dreams, imaginary, jouissance, Luso-Brazilian culture

(La fantaisie ne dort pas: le langage de la nuit et les maux de l'illusion)

Dans le prolongement des études sur le maux de l'âme selon la culture luso-brésilienne et européenne du XVIe au XVIIIe siècle, cet article examine de différentes interprétations et utilisations des récits de songes. En particulier, il traite des troubles causés par les excès de la jouissance compris comme leurres du monde.

Mots clés: Maux de l'âme, songe, imaginaire, jouissance, culture luso-brésilienne

(La fantasía nunca duerme: lenguage de la noche y los males de la ilusión)

Continuando los estudios sobre los males del alma conforme la cultura luso-brasileña y europea de los siglos XVI al XVIII, este artículo investiga las diferentes interpretaciones y usos de las narrativas oníricas. En especial, trata de los desórdenes causados por los excesos del gozo comprendidos como engaños del mundo.

Palabras clave: Males del alma, sueño, imaginario, gozo, cultura luso-brasileña 
(Die Phantasie schläft nicht: die Sprache der Nacht und Leiden der Illusion)

In Fortsetzung der Untersuchungen der Seelenleiden, entsprechend der luso-brasilianischen und europäischen Kultur vom 16. bis 18. Jahrhundert, untersucht dieser Beitrag die unterschiedlichen Interpretationen und den Umgang mit den Traumerzählungen. Insbesondere behandelt es die Verwirrung infolge von Genussexzessen, die als Lockmittel der Welt betrachtet werden.

Schlüsselwörter: Seelenleiden, Traum, Fantasiewelt, Genuss, luso-brasilianische Kultur

Citação/Citation: Carvalho da Silva, P. J. (2013, dezembro). A fantasia não dorme: linguagem da noite e males da ilusão. Revista Latinoamericana de Psicopatologia Fundamental, 16(4), 597-609.

Editor do artigo/Editor: Prof. Dr. Paulo José Carvalho da Silva

Recebido/Received: 10.10.2013/ 10.10.2013 Aceito/Accepted: 20.10.2013/10.20.2013

Copyright: (C) 2009 Associação Universitária de Pesquisa em Psicopatologia Fundamental/ University Association for Research in Fundamental Psychopathology. Este é um artigo de livre acesso, que permite uso irrestrito, distribuição e reprodução em qualquer meio, desde que o autor e a fonte sejam citados / This is an open-access article, which permits unrestricted use, distribution, and reproduction in any medium, provided the original author and source are credited.

Financiamento/Funding: Esta pesquisa é financiada pelo Conselho Nacional de Desenvolvimento Científico e Tecnológico - CNPq (Brasília, DF, Br)/ This research is funded by National Counsel of Technological and Scientific Development (Brasília, DF, Br).

Conflito de interesses/Conflict of interest: $\mathrm{O}$ autor declara que não há conflito de interesses / The author declares that has no conflict of interest.

\section{Paulo José Carvalho da Silva}

Psicólogo; Psicanalista; Mestre em História da Ciência pela Pontifícia Universidade Católica de São Paulo - PUC-SP; Doutor em Psicologia pela Universidade de São Paulo - USP (São Paulo, SP, Brasil); Professor doutor da Faculdade de Psicologia da PUC-SP (São Paulo, SP, Brasil); Membro da Associação Universitária de Pesquisa em Psicopatologia Fundamental (São Paulo, SP, Brasil).

Rua Monte Alegre, 984

05015-001 São Paulo, SP, Brasil

Fone: (11) 99248-9202

e-mail: paulojcs@hotmail.com 